\title{
Nursing Guidelines for Patients with Diabetic Foot Awareness about Hyperbaric Oxygen Therapy
}

\author{
Mariam leuies Abed Elmaseh ${ }^{1}$, Magda Amhed Mohammed ${ }^{2}$, Hanan Mahmoud Ahmed ${ }^{3}$ \& Ghada Hassan \\ Ahmed $^{4}$ \\ 1. B.SC, Faculty of Nursing, Assiut University, Assiut, Egypt. \\ 2. Professor, Medical Surgical Nursing Department, Faculty of Nursing, Assiut University, Assiut, Egypt. \\ 3. Professor, Internal Medicine Department, Faculty of Medicine, Assiut University, Assiut, Egypt. \\ 4. Lecturer, Medical Surgical Nursing Department, Faculty of Nursing, Assiut University, Assiut, Egypt.
}

\begin{abstract}
Aims: Was to evaluate the effect of applying nursing guidelines on patients' awareness about HBOT. Research design: auasi experimental design has been used to carry out this study on a sample of 200 adult diabetic patients both sex since two years ago within 6 months. Study was conducted at internal medicine department and diabetic outpatient clinic at Assiut University Hospitals. Tools: Three tools used; A structured interview questionnaire sheet, Designed Nursing guidelines and Patient evaluation sheet. Results: Out of 200 patients, the highest percent of studied sample were male $(53.3 \%)$, their age 50- 65 years $(39.5 \%)$ married and living in rural area (80.5), read and write $(59.0 \%)$, not working $(59.0 \%),(84.0 \%)$ had family history from other relatives, and $(33.0 \%)$ of patients were having hypertension with diabetes mellitus and the majority (ninety five percent and(hundred percent) had poor level of knowledge about diabetic foot and HBOT during pre-test followed by (hundred percent), (ninety percent) had good knowledge level about diabetic foot and HBOT after implementation nursing guidelines. Conclusion: Diabetic foot patients exposed to several complications, improving patient's awareness about HBOT can favorable affect the incidence of these complications. Recommendation: Organize regular counseling sessions for meeting the patients' information about diabetic foot and HBOT.
\end{abstract}

\section{Keywords: Diabetic Foot, Hyperbaric Oxygen Therapy \& Nursing Guidelines.}

\section{Introduction}

Foot ulcers in diabetics are considered the most common and serious problem of diabetes. Treatment often needs long-term medical institution admissions and frequent outpatient visits. Furthermore, lack of mobility poses an exquisite burden on the patient and the health care system (Yazdanpanah et al., 2015).

According to the WHO international Diabetes Report Within this population, the prevalence of diabetic foot ulcers (DFUs) is reported to be four percent to ten percent, with a one-in-four risk of ulceration at some stage in a life-time (Anon, 2016).

Diabetic foot ulcers is characterized through a classical triad of neuropathy, ischemia, and infection because of the impaired metabolic mechanisms in diabetes mellitus, may be an expanded danger of infection and poor wound healing due to a chain of mechanisms which include reduced cellular and growth aspect reaction, diminished peripheral blood flow and reduced local angiogenesis. Consequently, the feet are predisposed to peripheral vascular problem, damage of peripheral nerves, deformities, ulcerations and gangrene (Simerjit et al., 2013).

Hyperbaric oxygen therapy (HBOT) has been promoted as an effective assistive therapy for managing the foot wounds of the diabetic sufferers.
The effects of HBOT on improving wound tissue hypoxia make it a beneficial adjunct in scientific exercise for diabetic foot ulcers. It could reduce the hazard of lower-extremity amputation and improve healing in people with diabetes with foot ulcers (Oliveira et al., 2014).

HBOT: A scientific remedy in which the affected person is enclosed in a strain chamber respiration of hundred percentage concentration oxygen (O2) at more than one atmosphere (atm) pressure. Either a monoplace chamber pressurized with pure oxygen or a bigger multiplace chamber (United Health Care Medicare, 2017).

HBOT takes advantage of the fact that oxygen is transported in the blood; increasing atmospheric pressure therefore maximizes tissue oxygenation and stimulate wound repair (Singh \& Gambert, 2014). HBOT can be used as primary remedy for embolisms (air or gas bubbles within the blood movement), carbon monoxide poisoning (from inhaling smoke or car exhaust), gas gangrene, crush injury, compartment syndrome and other severe injuries (as an example, frostbite), decompression illness, enhancing the restoration of wounds along with ulcers in diabetic foot, anemia, abscess Intracranial, infections that causes necrosis of the soft tissue, osteomyelitis (bone infection) and delayed radiation trauma (Evans et al., 2015). 
HBOT remedy contraindications include: claustrophobia, pneumothorax, chronic obstructive pulmonary disease, seizure disorders, upper respiratory infection, hyperthermia, malignant tumors, acidosis, anxiety, gas emboli/tension, increased lung bleb and accelerated hazard of seizure (Ling et al., 2015).

The commonest side effects of hyperbaric oxygen therapy are ear and sinus barotrauma, myopia, oxygen toxicity, Fires inside chamber may additionally arise. To minimize the chance of complications, sufferers should be very well screened and monitored during their treatment by way of skilled hyperbaric physicians and nurses (Sharkey, 2010).

Particular instructions to the patient previous to treatment with oxygen under pressure encompass work on the chest X-ray to make sure they are free of disease, and examine ear, nose to make sure the integrity of the channel Astekeus and they are open in addition to the bottom of the eye to hit upon sufferers retina (Evans et al., 2015).

\section{Significance of the study}

Patient with diabetic foot ulcers require long hospitalization, considerable burden on patients and health- care service resources and carry the risk of amputation. According to hospital registry about 1660 patients diagnosed with diabetes mellitus in 2016, out of those cases, 184 patients were having diabetic foot (Hospital Record \& Assiut University, 2016). Unfortunately, there is a gap of knowledge about (HBOT) among diabetic sufferers at Assiut university hospital and this study is considered the first one in this area of research. This study conducted to provide patients with nursing guidelines that provide information about diabetic foot and hyperbaric oxygen therapy.

\section{The Aims of the Study}

Through the following:

1- Assess patient's awareness about diabetic foot and hyperbaric oxygen therapy.

2- Develop and implement nursing guidelines for patients with diabetic foot about hyperbaric Oxygen therapy.

3- Evaluate the effect of applying the nursing guidelines on patient's awareness about hyperbaric oxygen therapy.

\section{Research hypothesis}

Patients with diabetic foot who will receive the nursing guidelines would be more aware about diabetic foot and hyperbaric oxygen therapy than pre application of the nursing guidelines.

\section{Subjects \& Method}

Research design: Quasi (Pre-Post-test) experimental design has been used to carry out this study.

Setting: This study has been carried out in the internal medicine department and diabetic foot outpatient clinic at Assiut university hospital.

Sample: This study included two hundred adult patients diagnosed with diabetes within six months period according to the following criteria (age ranged from eighteen to sixty five years, both sex and have diabetes since two years ago) and were agree to participate in the study.

Study tools: Three tools have been used to gather information for the prevailing study

Tool (I): A structured interview questionnaire: (three parts) Part (1): It included biosocidemographic characteristics and medical data of the study participants (200 patients) such as age, gender, marital status, occupation, level of education, residence, family history, disease duration and other chronic disease.

Part (2): Used to asses patient's awareness about diabetic foot which included; (definition of diabetes and diabetic foot, risk factors, clinical manifestations, complications, management, why the foot affected and methods of treatment).

Part (3): utilized to evaluate sufferer's awareness about hyperbaric oxygen therapy which encompassed; (hearing about hyperbaric oxygen therapy, definition, indications, contraindications, benefits, methods of treatment, mechanism of action, complications, duration of session and instructions before and after treatment).

\section{Tool (I I): The Designed Nursing Guidelines}

The content of nursing guidelines has been developed by the researcher according to literature review and sufferers' assessment needs and revised by experts in medical and nursing fields. It included knowledge about diabetic foot and hyperbaric oxygen therapy. The content of nursing guidelines was discussed with the patients in short sessions (two sessions) each session time ranged from 15-20 minutes.

\section{Tool (111) Patient's evaluation}

This tool was immediately done to evaluate the effect of nursing guidelines on patient's awareness about HBOT by using tool (I) part $(2,3)$.

\section{Scoring system}

Regarding patient knowledge about diabetic foot, this part include eight questions as (definition of diabetes, definition of diabetic foot, risk factors....etc) and hyperbaric oxygen therapy include eleven questions as (hearing about hyperbaric oxygen therapy, definition, indication, contraindications benefits....ets) : that uses a Likert scale. Scores for each item are between one and three points as follows; (I know, don't know, and have no idea). 
Range of total scores lie among nineteen to fifty seven points, considering a good knowledge level as fifty percent of the range of total score.

\section{Methodology}

- A written consent to conduct the study has been acquired from the directors of internal medicine and diabetic outpatient clinic at Assiut University Hospital to gather the needed data after study aim explanation.

- Validity and reliability of the tools was performed by 5 expertise ( 3 nurses and 2 medical staff) who reviewed the tools for clarity, relevance, comprehensiveness, understanding, applicability for pilot study and easiness for administration minor modifications were required. The content validity of this tool was checked by expert professors in the fields of medicine and nursing and correction was carried out accordingly.

- A pilot study has been performed on ten percent (twenty patients) of the sample to examine the applicability and feasibility of the developed tools. Minimal modifications are required. Those patients who were involved in the pilot study were included in the actual study after these modifications were done.

- The researcher interviewed individually every patient to assess his awareness about HBOT, the questionnaire has been filled by the asking the patient $\&$ documented their answers within twenty minutes.

- Nursing guidelines application has been carried out by the researcher using tool II and evaluation of the effect of the designed guidelines on awareness was done by the researcher using tool III within fifteen to twenty minutes.

- Data were collected from the previous mentioned places during the period from January till June 2017.

\section{Ethical considerations}

1- Research proposal has been approved from Ethical Committee in the Nursing College.

2- There is no risk for study patients during research application.

3- Studies participants can refuse to participate or withdraw from the study at any time.

4- An oral permission for participation voluntarily has been acquired from patients. The researcher initially introduced herself to patients to initiate line of communication and they were assured that the collected data would be absolutely confidential. Confidentiality of the patient's data has been assured.

\section{Statistical Analysis}

Entry of data and statistical analysis has been performed by the usage of SPSS version 20.0. Data has been presented using descriptive statistics in the form of frequencies and percentages for qualitative variables, and means and standard deviations, the relationship between awareness of HBOT and demographic characteristics such as age, sex, level of education and occupation, was assessed using chisquare test, a two-tailed test $\mathrm{P}$-value of less than 0.05 was considered statistically significant. 
Results

Table (1): Distribution of patients according to their demographic characteristics $(n=200)$.

\begin{tabular}{|l|c|c|}
\hline \multicolumn{1}{|c|}{ Characteristics } & $\mathbf{N}$ & \% \\
\hline Age groups: & \multicolumn{2}{c|}{} \\
18-<28 years & 40 & 4.5 \\
29-<39 years & 72 & 20.0 \\
40-49 years & 79 & 36.0 \\
50-65 years & \multicolumn{2}{|c|}{$\mathbf{4 6 . 1 1 \pm 9 . 1 8}$} \\
\hline Mean +SD & 107 & \\
\hline Sex: & 93 & 53.5 \\
Male & & 46.5 \\
Female & 27 & \\
\hline Marital status: & 148 & 13.5 \\
Single & 21 & 74.0 \\
Married & 4 & 10.5 \\
Divorced & & 2.0 \\
widow & 106 & \\
\hline Level of education: & 17 & 83.0 \\
\hline Read and write & 5 & 2.5 \\
Primary school & 43 & 21.5 \\
Secondary school & 29 & 14.5 \\
Propartery & & \\
University & 82 & 41.0 \\
\hline Occupation: & 118 & 59.0 \\
\hline Working & & \\
Not working & 39 & 19.5 \\
\hline Residence : & 161 & 80.5 \\
\hline Urban & & \\
Rural & & \\
\hline
\end{tabular}

Table (2): Percentage distribution of the studied patients regarding family history, presence of other disease and duration of diabetes $(n=200)$.

\begin{tabular}{|l|c|c|c|c|}
\hline \multirow{2}{*}{ Variables } & \multicolumn{2}{c|}{ Yes } & \multicolumn{2}{c|}{ No } \\
\cline { 2 - 5 } & $\mathbf{N}$ & $\mathbf{\%}$ & $\mathbf{N}$ & \% \\
\hline Family history of diabetes : & 168 & 84.0 & 32 & 16.0 \\
\hline If yes & & & & 0 \\
\hline Father & 13 & 6.5 & 0 & 0 \\
Mother & 47 & 23.5 & 0 & 0 \\
Relative & 108 & 54.0 & 0 & 0 \\
\hline Other disease: & 74 & 37.0 & 126 & 63.0 \\
\hline If yes & & & & \\
\hline Blood disease & 3 & 1.5 & 0 & 0 \\
Hypertension & 66 & 33.0 & 0 & 0 \\
Kidney disease & 2 & 1.0 & 0 & 0 \\
Other disease & 3 & 1.5 & 0 & 0 \\
\hline Duration of diabetes: & 142 & 71.0 & - & - \\
\hline 1-5yrs & 43 & 21.5 & - & - \\
6-10 yrs. & 15 & 7.5 & - & - \\
more than 10 yrs.
\end{tabular}


Table (3): Comparison between pre-posttest of patient's level of knowledge regarding diabetic foot knowledge

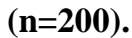

\begin{tabular}{|l|c|c|c|c|c|c|c|c|c|}
\hline \multirow{2}{*}{ Knowledge about diabetic foot } & \multicolumn{4}{|c|}{ Pretest } & \multicolumn{4}{c|}{ Posttest } & \\
\cline { 2 - 12 } & \multicolumn{2}{|c|}{ good } & \multicolumn{2}{|c|}{ poor } & \multicolumn{2}{|c|}{ good } & \multicolumn{2}{|c|}{ poor } & \multirow{2}{*}{ p.value } \\
\cline { 2 - 12 } & $\mathbf{N}$ & $\mathbf{\%}$ & $\mathbf{N}$ & $\mathbf{\%}$ & $\mathbf{N}$ & $\mathbf{\%}$ & $\mathbf{N}$ & $\mathbf{\%}$ & \\
\hline - Definition of diabetes mellitus. & 17 & 8.5 & 183 & 91.5 & 194 & 97.0 & 6 & 3.0 & $0.00^{* *}$ \\
\hline - Define diabetic foot. & 6 & 3.0 & 194 & 97.0 & 192 & 96.0 & 8 & 4.0 & $0.00^{* *}$ \\
\hline - Risk factors of diabetic Foot. & 12 & 6.0 & 188 & 94.0 & 171 & 85.5 & 29 & 14.5 & $0.00^{* *}$ \\
\hline $\begin{array}{l}\text { - Signs and symptoms of diabetic } \\
\text { foot. }\end{array}$ & 19 & 9.5 & 181 & 90.5 & 177 & 88.5 & 23 & 11.5 & $0.00^{* *}$ \\
\hline - Why foot affected? & 4 & 2.0 & 196 & 98.0 & 199 & 99.5 & 1 & 0.5 & $0.00^{* *}$ \\
\hline - Prevention of diabetic foot. & 12 & 6.0 & 188 & 94.0 & 193 & 96.5 & 7 & 3.5 & $0.00^{* *}$ \\
\hline - Harmful of diabetic foot. & 62 & 31.0 & 138 & 69.0 & 200 & 100 & 0 & 0 & $0.00^{* *}$ \\
\hline - Method of treatment. & 42 & 21.0 & 158 & 79.0 & 189 & 94.5 & 11 & 5.5 & $0.00^{* *}$ \\
\hline
\end{tabular}

Table (4): Comparison between pre -posttest of patient's level of knowledge regarding hyperbaric oxygen therapy.

\begin{tabular}{|c|c|c|c|c|c|c|c|c|c|c|c|c|c|}
\hline \multirow{3}{*}{$\begin{array}{c}\text { Knowledge about hyper baric } \\
\text { oxygen therapy }\end{array}$} & \multicolumn{6}{|c|}{ Pretest } & \multicolumn{6}{|c|}{ Post test } & \multirow{3}{*}{ p.val } \\
\hline & \multicolumn{2}{|c|}{ Yes } & \multicolumn{2}{|c|}{ No } & \multicolumn{2}{|c|}{$\begin{array}{l}\text { Don't } \\
\text { know }\end{array}$} & \multicolumn{2}{|c|}{ Yes } & \multicolumn{2}{|c|}{ No } & \multicolumn{2}{|c|}{$\begin{array}{c}\text { Don' } \\
\text { t } \\
\text { know }\end{array}$} & \\
\hline & $\mathbf{N}$ & $\%$ & $\mathbf{N}$ & $\%$ & $\mathbf{N}$ & $\%$ & $\mathbf{N}$ & $\%$ & $\mathbf{N}$ & $\%$ & $\mathbf{N}$ & $\%$ & \\
\hline $\begin{array}{l}\text { - Hearing about hyperbaric oxygen } \\
\text { therapy. }\end{array}$ & 0 & 0 & 0 & 0 & 200 & 100 & 200 & 100 & $\mathbf{0}$ & 0 & 0 & 0 & 0.00 ** \\
\hline $\begin{array}{l}\text { - Definition of hyperbaric oxygen } \\
\text { therapy. }\end{array}$ & 0 & 0 & 0 & 0 & 200 & 100 & 199 & 99.5 & 1 & 0.5 & 0 & 0 & 0.00 ** \\
\hline $\begin{array}{l}\text { - Indication of hyperbaric oxygen } \\
\text { therapy. }\end{array}$ & 0 & 0 & 0 & 0 & 200 & 100 & 167 & 83.5 & 33 & 16.5 & 0 & 0 & 0.00 ** \\
\hline $\begin{array}{l}\text { - Contraindication of hyperbaric } \\
\text { oxygen therapy. }\end{array}$ & 0 & 0 & 0 & 0 & 200 & 100 & 99 & 49.5 & 101 & 50.5 & 0 & 0 & 0.00 ** \\
\hline $\begin{array}{l}\text { - Advantages of hyperbaric oxygen } \\
\text { therapy. }\end{array}$ & 0 & 0 & 0 & 0 & 200 & 100 & 170 & 85.0 & 30 & 15.0 & 0 & 0 & 0.00 ** \\
\hline $\begin{array}{l}\text { - Method of treatment of hyperbaric } \\
\text { oxygen therapy. }\end{array}$ & 0 & 0 & 0 & 0 & 200 & 100 & 174 & 87.0 & 26 & 13.0 & 0 & 0 & 0.00 ** \\
\hline $\begin{array}{l}\text { - Mechanism of hyperbaric oxygen } \\
\text { therapy. }\end{array}$ & 0 & 0 & 0 & 0 & 200 & 100 & 40 & 20.0 & 160 & 80.0 & 0 & 0 & $0.00^{* * *}$ \\
\hline $\begin{array}{l}\text { - Complications of hyperbaric } \\
\text { oxygen therapy. }\end{array}$ & 0 & 0 & 0 & 0 & 200 & 100 & 106 & 53.0 & 94 & 47.0 & 0 & 0 & $0.00 * *$ \\
\hline $\begin{array}{l}\text { - Duration of session for hyperbaric } \\
\text { oxygen therapy. }\end{array}$ & 0 & 0 & 0 & 0 & 200 & 100 & 199 & 99.5 & 1 & 0.5 & 0 & 0 & 0.00 ** \\
\hline $\begin{array}{l}\text { - Preparation before session for } \\
\text { hyperbaric oxygen therapy. }\end{array}$ & 0 & 0 & 0 & 0 & 200 & 100 & 187 & 93.5 & 13 & 6.5 & 0 & 0 & $0.00^{* * *}$ \\
\hline $\begin{array}{l}\text { - Instructions follow after session of } \\
\text { hyperbaric oxygen therapy. }\end{array}$ & 0 & 0 & 0 & 0 & 200 & 100 & 165 & 82.5 & 35 & 17.5 & 0 & 0 & 0.00 ** \\
\hline
\end{tabular}

Table (5) Comparison between pre -posttest of patients level of knowledge regarding hyperbaric oxygen therapy $n=200$

\begin{tabular}{|c|c|c|c|c|c|c|c|c|c|}
\hline \multirow{3}{*}{ Total knowledge } & \multicolumn{4}{|c|}{ Pretest } & \multicolumn{4}{|c|}{ Posttest } & \multirow{3}{*}{ p.value } \\
\hline & \multicolumn{2}{|c|}{ poor } & \multicolumn{2}{|c|}{ good } & \multicolumn{2}{|c|}{ poor } & \multicolumn{2}{|c|}{ good } & \\
\hline & $\mathbf{N}$ & $\%$ & $\mathbf{N}$ & $\%$ & $\mathbf{N}$ & $\%$ & $\mathbf{N}$ & $\%$ & \\
\hline Diabetic foot & 189 & 94.5 & 11 & 5.5 & 0 & 0 & 200 & 100 & 0.00 \\
\hline $\begin{array}{l}\text { Hyperbaric oxygen } \\
\text { therapy }\end{array}$ & 200 & 100 & 0 & 0 & 20 & 10 & 180 & 90 & 0.00 \\
\hline
\end{tabular}


Table (1) Shows that the highest percent of studied sample were male $(53.3 \%)$, their age $50-65$ years $(39.5 \%)$ married and living in rural area $(80.5)$, able to read and write (53.0\%) and not working (59.0).

Table (2): Shows that; $(84.0 \%)$ of the studied patients had family history from other relatives, duration of diabetes; it was found that $(71.0 \%)$ of them discovered diabetes within one to five years and $(33.0 \%)$ of patients were having hypertension with diabetes mellitus.

Table (3): Revealed that; the majority of the studied patients during the pretest period had poor level of knowledge regarding definition of diabetes, definition of diabetic foot, risk factor of diabetic foot, why the foot affected, prevention of diabetic foot $(91.5 \%$, 97.05, 94.05, 90.5\%, 98.0\%, $94.0 \%$ ) respectively. On the other hand, the majority of patients during the post-test were having good level of knowledge about harm of diabetic foot, why the foot affected, definition of diabetes, definition of diabetic foot, prevention of diabetic foot and methods of treatment (100.0\%, 99.5\%, 97.0\%, 96.5\%, 96.0\%, 94.5\%) respectively. Finally, this table demonstrates that significant difference was found between pre and posttest of patients as regard diabetic foot knowledge $(\mathrm{p}=0.00)$.

Table (4): Illustrated that all the studied patients $(100 \%)$ have poor level of knowledge about hyperbaric oxygen therapy during the pre-test .On the other hand, majority $(100 \%, 99.5 \%, 99.5 \%$, and $93.5 \%$ ) of the studied patients had good level of knowledge during the post test regarding hyperbaric oxygen therapy, definition, duration of session therapy and preparation before hyperbaric oxygen therapy session. Finally, this table showed that, significant difference between pre and post test of patients regarding hyperbaric oxygen therapy knowledge $(\mathrm{p}=0.00)$.

Table (5): Clarify that the majority (94.5\%) and $(100 \%)$ of the studied patients had poor level of knowledge about diabetic foot and hyperbaric oxygen therapy during pre-test followed by $(100 \%)$ and $(90 \%)$ had good level of knowledge about diabetic foot and hyperbaric oxygen therapy during post-test. Finally this table mentioned that, significant difference was found between pre and posttest knowledge regarding diabetic foot and hyperbaric oxygen therapy $(\mathrm{p}=0.00)$.

\section{Discussion}

According to the prevailing study results; the highest percentage of the studied participants their age ranged from fifty to sixty five years, male and married. Regarding level of education; it has been found that more than half of the studied patients were able to read and write. These finding was in line with
Al-Wahbi (2010) \& Maria et al., (2016) who reported that; the majority of the studied sufferers their age was fifty to sixty two years old, two thirds of them were male, three quarters were married and more than fifty percent of them have poor educational level.

Regarding discovery of the disease; the result of the present study revealed that more than two thirds of patients discovered diabetes one to five years ago. This result disagree with Khattab \& Abd El Fattah,(2015) who reported that more than one quarter of the patients discovered diabetes from five to ten years ago due to diabetic patients become more aware about diabetes from media, television, and newspapers.

In the current study more than three quarters of the studied patients had family history from relative and one third of patients have hypertension with diabetes. This result disagrees with Khattab \& Abd El Fattah, (2015) who stated that the majority of patients were having hypertension with parental family history.

The majority of patients with diabetic foot were living in rural area. This finding is consistent with Akther et al., (2011) who reported that the most common participants lived in a rural area.

Concerning occupation the result of the current study demonstrate that more than half of patients were notworking. This finding was in line with Ahamed et al., (2016) who stated that the highest percentage of patients was not working.

Regarding the knowledge of the patients about diabetic foot, the present study results clarify that the majority of the studied sufferers during the pretest had a poor knowledge level related to definition of diabetes, definition of diabetic foot, risk factor of diabetic foot, why the foot affected and prevention of diabetic foot, but regarding harmful effects of diabetic foot it has been discovered that more than two thirds of patients had a good knowledge level. Concerning the method of treatment for diabetic foot it has been reported that more than three quarters had good level of knowledge. On the other hand, during posttest, the majority of the studied patients had a good knowledge level about diabetic foot.

This finding was supported by Waheida \& Bassuni, (2015) who stated that; there was an improvement of patients' knowledge about diabetic foot in all items after providing the nursing guidelines for the studied patients.

In the present study the majority of the studied patients were not having knowledge about how to prevent diabetic foot infection before providing knowledge (nursing guidelines) as walking bare shoes, not drying the feet after washing, wearing open shoes and wearing shoes without socks or 
observing it before wearing the shoes, but such knowledge improved post providing nursing guidelines.

According to, Al Arouj, (2014) risk factors for diabetic foot complications are particularly relevant to the Arab world. These results are because of hot, dry weather, which means sandals are a common choice of foot wear or people frequently chose to go barefoot, out of habit or necessity. This leaves the foot open to trauma and this can lead to infection. Also Basal, (2005) reported that the effect of health education program will reflect on knowledge towards appropriate foot care, and preventing the progress of foot ulcer and amputation.

The current study revealed that the majority of the studied patients had poor knowledge regarding diabetic foot during pretest, but during posttest it was observed that the majority of patients had good knowledge. This finding is congruent with the study of Waheida \& Bassuni, (2015) who found that there was an improvement in patients' knowledge for diabetic foot in all items after post program.

Concerning knowledge of patients about hyperbaric oxygen therapy (HBOT) the prevailing study clarified that all the studied patients had poor level of knowledge about hyperbaric oxygen therapy; (hearing about HBOT, definition, indications, contraindications, benefits, methods of treatment, mechanism, complications, duration of session, preparation before treatment and instructions after treatment) during the pretest. From the researcher's opinion this impairment of knowledge in the present period may be attributed to two reasons; first, lack of health educational mass campaigns about the HBOT and the way of treatment for diabetic foot. Secondary, lower educational degree of the studied sample (more than half of patients were poorly educated).

The studied patient participants showed an improvement in their knowledge level about the hearing about and definition of HBOT post test than pre test. This finding disagrees with Bishop \& Mudge, (2014) who reported that most patients have heard about HBOT through chance circumstances; for example, through a neighbor, friend, or health care provider.

According to indications of HBOT the current study represented that; the majority of the study sample had poorly knowledge during pre-test. On the other hand, during posttest, the present study showed that; more than quarter of the studied patients had good knowledge about indications of HBOT within nursing guidelines. This result was consistent with Ling Yan et al., (2015) who reported that; HBOT have emergency and non-emergency indications as gas gangrene, carbon monoxide, diabetes and diabetic foot and other diseases.
Patients' knowledge about contraindications of HBOT showed progress as all patients did not know HBOT contraindications pretest while nearly halfe of them had a good knowledge level posttest. This finding agree with Aalaa et al., (2012) who demonstrated that HBOT have absolute and relative contraindications as cardiac diseases, pneumothorax, high fever and malignant diseases.

The same thing happened to the patient's knowledge about the advantages of HBOT as all of them had poor level pretest while in post-test greater than quarter of them had a good level. This finding agree with Benjamin \& Lipsky, (2010) who reported that HBOT significantly completed ulcer healing and reduced the risk of major amputation and may improve the chance of healing at 1 year. And Londahl et al., (2010) reported that multiplace hyperbaric chamber and monoplace hyperbaric chamber are methods for treatment.

The present study revealed that the majority of patients had poor level of knowledge about mechanism of HBOT during pre-test, while on the other hand less than half of patients had good knowledge about mechanism of HBOT during posttest. This finding was in the same line with Huang et al., (2015) who reported that; HBOT is an effective treatment of diabetic foot ulcers by increasing oxygen and blood flow to the damaged areas and increase vasoconstriction, angiogenesis, fibroblast proliferation, leukocyte oxidative killing, toxin inhibition and antibiotic action.

Also, patients' knowledge about HBOT complications all patients was obtaining poor level while majority of them obtained a good level of knowledge. This result is congruent with Thom, (2011) who stated that although HBOT is generally regarded as a safe treatment, there are several complications as ear and sinus barotrauma, developing cataract after prolonged series of HBOT beside other complications.

Additionally the majority of studied patients had a poor level about session duration of HBOT pretest while the majority of them had a good level post test. This finding is congruent with Löndahl, (2012) who demonstrated a significantly improved outcome in the intervention group as the treated patients were more likely to heal within 12 months. And Health Quality Ontario, (2017) reported that; patients were required to attend daily sessions for at least one hour at a time. Regarding knowledge of patients about instructions after the session of HBOT, the majority of patients had poor knowledge at pre-test. On the other hand, more than three quarters of patients had good knowledge about instructions following the session of HBOT during post-test. This finding is consistent with Bhutani \& Vishwanath, (2012) who reported 
that; the nursing care for patients undergoing HBOT must primarily focus on patient education, patient monitoring, and the continuous evaluation of the healing process. Therefore, nurses should work with the interdisciplinary team, with the patient, and family to determine the educational needs and perform the relevant interventions. The hypotheses were supported as most common participants had good knowledge about diabetic foot and hyperbaric oxygen therapy after implementation the nursing guidelines.

\section{Conclusion}

Patients with diabetes and diabetic foot ulcer had poor level of knowledge about diabetic foot and hyperbaric oxygen therapy during the pre-test; but after providing the nursing guidelines (Booklet) for diabetic foot ulcer patients there was a significant improvement in patient's awareness about diabetic foot and hyperbaric oxygen therapy.

\section{Recommendations}

1. Action plan to educate patients newly diagnosed with diabetes about this disease.

2. Providing a written instructions booklet about diabetic foot and hyperbaric oxygen therapy is of great importance for the patients.

3. Organize regular counseling sessions for meeting the patient's information needs about diabetic foot and hyperbaric oxygen therapy and solving their problems by providing them with clear, full and accurate information in both verbal and written form.

4. Mass media, radio, TV and newspapers should provide programs about preventive measures for diabetic foot and management with hyperbaric oxygen therapy.

5. Providing treatment with hyperbaric oxygen therapy in Assiut university hospital.

\section{References}

1. Aalaa M., Malazy O., Sanjari M., Peimani M., \& Mohajeri- Tehrani M., (2012): Nurses' role in diabetic foot prevention and care; a review. J Diabetes Metab Disord; Pp.11-24.

2. Ahamed S., Mohamed M., Zaky S., (2016): Prevalence of Risk Factors for Egyptian Diabetic Foot Ulceration. IOSR Journal of Nursing and Health Science Volume ( 5), Issue( 2), Pp. 45-55.

3. Akther J., Khan I., Shahpurkar V., \& Khanam N., (2011): Evaluation of the diabetic footaccording to Wagner's classification in a rural teaching hospital. Br J Diabetes Vasc Dis. 2011;11:74-79.
4. Al Arouj M., (2014): Improve Diabetic Foot Care in Arab World, Excellence in Diabetes 2014 conference, 28 February, volume (9), Issue (19) P.p, 675-700.

5. Al-Wahbi, A., (2010): Impact Of A Diabetic Foot Care Education Program On Lower Limb Amputation Rate, Vascular Health and risk Management,V.( 6): Pp 923934.

6. Anon H., (2016): Global Report on Diabetes. World Health Organization. Available at: http://apps.who.int/irisbitstream/10665/204871/ 1/9789241565257_eng.pdf. (accessed May 17, 2016)

7. Basal A., (2005): Comparative Study between Three Wound Dressing Techniques for Diabetic Foot Ulceration,.Doctoral Dissertation Faculty of Nursing. Tanta University.

8. Benjamin A., \& Lipsky M., (2010): Hyperbaric Oxygen Therapy for Diabetic Foot Wounds Has hope hurdled hype? Journal list Diabetes Care. 2010 May; Volume (33), Issue (5), Pp. 1143-1145.

9. Bhutani S., \& Vishwanath G., (2012): Hyperbaric oxygen and wound healing. Indian J PlastSurg.Volume (45), Issue (2), Pp. 316-324.

10. Bishop A., \& Mudge E., (2014): Diabetic foot ulcers treated with hyperbaric oxygen therapy: a review of the literature. Int Wound J. 2014; Volume (11), Issue (1), Pp. 28-34.

11. Evans A., GavinWort C., \& janiss R., (2015): Eleective hyperbaric oxygen therapy .pp:6-7.

12. Health Quality Ontario, (2017): Hyperbaric oxygen therapy for the treatment of diabetic foot ulcers: a health technology assessment. Ont Health Technol Assess Ser [Internet]. 2017 May, volume (17), Issue (5), Pp. 137-142.

13. Hospital Record - Assiut University, (2016).

14. Huang E., Mansouri J., Murad M., Joseph W., Strauss M., \& Tettelbach W., (2015): A clinical practice guideline for the use of hyperbaric oxygen therapy in the treatment of diabetic foot ulcers. Undersea Hyperb Med. 2015; Volume (42) Issue (3), Pp. 205-47.

15. Khattab S., \& Abd El Fattah A., (2015): Effect of an Educational Program on Caregivers, Knowledge about Diabetic Foot Care atElderly Home in Damanhur- Egypt. Journal of American Science 2015; 11(1).

16. Ling Yan, Ting Liang \& Oumei Cheng, (2015): hyperbaric oxygen therapy in China $\mathrm{P}$ p. 2-6. 
17. Löndahl M., Katzman P., Nilsson A., \& Hammarlund C., (2010): Hyperbaric oxygen therapy facilitates healing of chronic foot ulcers in patients with diabetes. Diabetes Care; Volume (33), Pp. 998-1003.

18. Londahl M., (2012): Hyperbaric oxygen therapy as treatment of diabetic foot ulcers. Diabetes Metab Res Rev. Volume (28), Suppl (1), Pp. 78-84.

19. Maria Teresa Verrone Quilici, Fernando de Sá Del Fiol, Alexandr Eduardo Franzin Vieira, \& Maria Inês Toledo, (2016): Risk Factors for Foot Amputation in Patients Hospitalized for Diabetic Foot Infection. Journal of Diabetes ResearchVolume (2), Pp.8-12.

20. Oliveira N., Rosa P., Borges L., Dias E., Oliveira F., \& Cássio I., (2014): Treatment of diabetic foot complications with hyperbaric oxygen therapy: a retrospective experience. Foot Ankle Surg. Volume (20), Pp. 140-143.

21. Sharkey S., (2010): Current indications for hyperbaric oxygen therapy. Journal of the Australian Defence Health Service (ADF Health) Volume (1), Pp. 64-7.

22. Simerjit Singh, Dinker R., Pai \& Chew Yuhhui. (2013): Diabetic Foot UlcerDiagnosis and Management . Clinical Research on Foot \& Ankle Received September 27, 2013; Accepted October 30, 2013; Published November 07, 2013.

23. Singh S., \& Gambert S., (2014): Hyperbaric oxygen therapy: a brief history and review of its benefits and indications for the older adult patient. Annals of Long-Term Care; Volume (22), Pp. 7-8.

24. Thom S., (2011): Hyperbaric oxygen: its mechanisms and efficacy. Plast Reconstr Surg. Volume (127), Supp. (1 1), Pp. 131-141.

25. United HealthCare Medicare Benefit Interpretation Committee (2017): Hyperbaric Oxygen Therapy. Pp. 1-5.

26. Waheida S., \& Bassuni M., (2015): Effect of Educational Program about Foot Care on Nurses' Knowledge, practice and Outcomes for Patients with Diabetes. IOSR Journal of Nursing and Health Science (IOSR-JNHS) Volume (4), Issue (6) Pp. 67-77.

27. Yazdanpanah L., Nasiri M., \& Adarvishi S., (2015): Literature review on the Management of diabetic foot ulcer. World J. Diabetes 2015; Volume (6), Pp. 37-53. 